down from $\$ 248$ million in 1982 to $\$ 83$ million in 1983. Energy conservation research would be reduced even more drastically, from $\$ 144$ million to $\$ 18$ million; both proposed cuts are expected to be challenged in Congress.

Another agency which has been the target of criticism from the private sector and which would also see its research budget cut under Mr Reagan's 1983 proposals is the Environmental Protection Agency, down from $\$ 317$ million to $\$ 230$ million.

Other research agencies, however, have done quite well, reflecting a broadly-based acceptance within the Administration that strong federal support for research and development is a legitimate claim on the public purse.

The National Science Foundation, for example, is listed for a budget increase of 7.5 per cent, with considerable real growth in areas such as computer research (up 14 per cent) to $\$ 29.3$ million, earth sciences (up 17.8 per cent) and mechanical engineering (up 13.7 per cent). The Administration has relented slightly in its efforts to cut back support for the social and economic sciences, having initially requested $\$ 10$ million in the 1982 budget, but now supporting a figure of $\$ 17.8$ million in 1983, the same level to which the 1982 budget was raised by Congress. However, it is sticking to its previous determination to eliminate virtually all science education activities sponsored by the National Science Foundation, arguing that education at the school level should remain primarily a responsibility of the states and local school boards.

The National Institutes of Health are scheduled for a modest 3.1 per cent increase in its research budget, slightly less than the anticipated rate of inflation. Unlike last year, the Administration is not seeking to eliminate institutional support for research training awards, a move which provoked a major outcry from biomedical research institutions.

Inevitably, budgetary stringencies have caused disappointments. The National Aeronautics and Space Administration, for example, has for the moment abandoned plans to send an orbiting imaging radar to Venus; but the rumoured extinction of the Galileo mission to Jupiter failed to materialize, and space science is scheduled for a healthy increase of almost 20 per cent, including full funding for the gamma-ray observatory, as well as sustained support for the space shuttle.

Dr George (Jay) Keyworth, the President's Science Advisor, said on Monday that he was "delighted" with the budget increase for science. He said that the physical sciences, once in jeopardy, had been spared during the review process to enable increased utilization of existing particle accelerators. "Next year", he said, "there will be more effort to separate the mediocre from the excellent in research."

David Dickson

\title{
US budget described in outline
}

\section{Energy support \\ Washington}

Not unexpectedly, the requested budget for the Energy Research and Technology Agency will contain strong support for the Clinch River liquid metal fast breeder reactor. The design and construction of the fast breeder are described as priorities and will receive $\$ 257$ million for the initiation of site preparation and continued procurement of parts.

However, work on both the Large Development Plant, started by the Carter Administration as an alternative to Clinch River, and the light water breeder reactor will be phased out, leading to an overall decrease of $\$ 108$ million from 1982 in spending on breeder reactors.

There will also be reduced support for fusion research, with the focus shifting from the construction of new facilities to what the Office of Management and Budget describes as "resolving key outstanding physics and technology issues". This will delay construction of the tandem mirror test facility at the Lawrence Livermore Laboratory, a decision which has contributed to the resignation of the head of the Department of Energy's fusion programme, Dr Edward Kintner.

Funds for inertial confinement fusion, until recently treated as a major alternative to the magnetic fusion programme, have also been reduced from $\$ 209$ million in 1982 to $\$ 119$ million in 1983 , again through shifting the focus from the completion of new facilities, such as Lawrence Livermore's Nova device, towards experiments on existing machines.

In contrast to the continued - if slightly reduced - support for research into nuclear fusion and fission, only $\$ 315$ million is being requested to support research in fossil, solar, biomass and other renewable energy sources, compared with $\$ 814$ million in 1982 .

\section{Unrest on loans}

If US universities have been relieved at escaping the prospect of heavy cuts in research spending, there is less consolation in the Reagan Administration's proposals to limit its assistance for students by reducing the support for the Guaranteed Student Loan (GSL) programme.

First introduced in 1965, the programme provides loan guarantees and interest subsidies to states, private lending institutions and eligible students. Under the present plans, federal support would increase from $\$ 3,397$ million in 1983 to $\$ 3,768$ by 1987 . Tightening up on eligibility requirements and increasing the costs of obtaining a guaranteed loan will result in savings of $\$ 912$ million in 1983 , rising to $\$ 2,247$ million by 1987 .

Loans to about 600,000 graduate students would disappear under plans to reduce by about a third the number of so- called Pell awards. Graduate students would be restricted to raising loans from the less-heavily subsidized GSL auxiliary loan programme, and lending institutions would be required to pay a higher insurance premium to the government.

The Administration claims that the cuts are justified on the grounds that the primary beneficiaries of the guaranteed loans have been "middle and upper income families", which had as a result been able to put their own savings into investment schemes yielding far higher returns. The universities, however, are worried that tightening up the loan conditions could lead to a severe drop in student numbers.

David Dickson

\section{ISABELLE}

Construction work on ISABELLE, the $400 \times 400 \mathrm{GeV}$ proton-proton accelerator at Brookhaven National Laboratory on Long Island, New York, will be halted under budget plans for the Department of Energy for 1983. However, development work will continue as an accelerator research and development programme on superconducting magnets.

In general, high-energy physics has done well in the budget proposals. Mr Reagan is seeking an increase of 17.5 per cent in funding to $\$ 429$ million, claiming this will allow increased use of existing research facilities, the completion of both the Energy Saver and the Tevatron I and II at Fermilab, and further research and development at the linear collider being planned by Dr Burton Richter at the Stanford Linear Accelerator Center.

Construction on ISABELLE, which started in 1978 and had been due for completion in 1987, has been held up largely due to difficulties with the magnets. Although these now appear to have been solved, the delays have meant extra expense. Last November, a special panel set up by the Department of Energy's High-Energy Physics Advisory Panel to look at the future of US high-energy physics concluded that ISABELLE was still important, but did not place its completion as a first priority in stringent budget conditions.

According to the Office of Management and Budget, the accelerator research at Brookhaven will be related to a "future high-energy physics accelerator project", and "any decision to proceed with this project will be based on overall scientific potential and budget considerations".

\section{Space science}

The Venus Orbiting Imaging Radar (VOIR) has been dropped from the National Aeronautics and Space Administration (NASA)'s list of future planetary exploration missions. However, the agency is discussing with space scientists the possibility of launching a 
cheaper version of the mission, using real rather than synthetic aperture radar, which could halve the estimated $\$ 500$ million cost and might still be launched by the end of the decade.

VOIR was initially proposed by the Carter Administration two years ago for a launch from the space shuttle in 1986, with the launch being merely postponed to 1988 by the Reagan Administration last March. It is the major casualty in NASA's space science budget, which otherwise is in a much healthier state than had been widely feared.

Both the Galileo mission to Jupiter and the gamma-ray observatory, which had been threatened by the Office of Management and Budget, have survived. Efforts to cut back substantially on space science seem to have been frustrated by strong pressure from the space science community, and fears that the cuts could have a traumatic effect on NASA's Jet Propulsion Laboratory in Pasadena, California.

NASA will not be providing any money for the development of the Centaur rocket as an upper stage for the space shuttle, previously suggested as an alternative to the delayed Inertial Upper Stage.

One area to be cut will be the analysis of data from other planetary missions, being reduced from $\$ 61.8$ million in 1981 to a suggested $\$ 26.5$ million in 1983. NASA officials say that although data will continue to be received and analysed from the Voyager spacecraft, now on their way to the outer planets, it may be necessary to stop tracking or taking data from the Pioneer spacecraft.

\section{Delay for Explorer}

The National Science Foundation has abandoned plans for a major deep-sea drilling programme aimed at investigating the margins of the continental shelf which was to have been conducted from the converted spy ship, Glomar Explorer.

Dr John Slaughter, director of the foundation, announced last Saturday that the Reagan Administration would not be requesting any further funds for the socalled ocean margin drilling programme, which was to have been jointly funded with a number of private oil companies.

According to Dr Slaughter there were two reasons for abandoning the project, first formally proposed by the Carter Administrtion two years ago: a lack of sufficient funding, given general pressures on the federal budget; and the lack of interest by companies in making the type of investment required to convert the Explorer and fully equip it.

The proposal has also been a controversial one in the scientific community, since it would have meant curtailing funds for the Glomar Challenger. Dr Slaughter said that a decision will be made next summer on whether to refurbish the Explorer as a replacement for Glomar Challenger.

\section{US defence research Signs of doubt}

\section{Washington}

The Reagan Administration is proposing in its latest budget recommendations to Congress (see p447) that there should be an increase in the amount of universitybased research sponsored by the Department of Defense in the fiscal year 1983 beginning on 1 October. But the universities themselves are ambivalent about this promise.

Many universities view Defense Department support as a necessary substitute for other federal funds whose sources are rapidly drying up. However, increased military spending on campuses is beginning to act as a catalyst for protest groups opposed to the Administration's policies.

University administrators seem to have fallen in with recent moves by the Department of Defense to increase support for basic research, while fearing some of the restrictions that this money may bring with it. Although many universities still insist that no classified research is carried out on campus, academic leaders have been quick to reassure Congress that little remains of the anti-military sentiment of the 1960s.

Dr Alan Bromley, for example, professor of physics at Yale University and president of the American Association for the Advancement of Science, told the House of Representatives science and technology subcommittee last week that the time to rebuild bridges between the Pentagon and the university research community was "long overdue".

Yet the enthusiasm for increased military support of university research is far from unanimous and there have already been rumblings of protest:

170 people from the University of California were arrested last Monday after demonstrating outside the Lawrence Livermore National Laboratory - run by the university on behalf of the Department of Energy - in protest at the laboratory's research on the design of nuclear weapons. - At the University of Michigan, the students' union has hired a historian to analyse the Defense Department's support of research in the university and in local companies.

A demonstration was held last summer at the University of Wisconsin's Madison campus over a visit by army scientists to the university's Mathematics Research Center, sponsored by the Department of Defense, to talk about military needs in mathematics. A group has since been formed to study the university's links with the Department of Defense, and a small organization has been set up to stimulate and coordinate efforts by similar groups elsewhere.

- At the Massachusetts Institute of Technology, about 1,000 people held a demonstration when Vice-President George Bush spoke to the institute's board of trustees. Several study groups have since been holding regular meetings on military topics, and 30 faculty members have just launched a disarmament project for the spring term.

There have been protests at Rutgers over a statement by its president, $\mathrm{Dr}$ Edward J. Bloustein at a congressional hearing last year that he would be prepared to consider lifting the current ban on classified research on the campus.

- Last November, "teach-ins" were held at 148 colleges and universities across the country on the arms race. The meetings were coordinated by the Boston-based Union of Concerned Scientists, which claimed that they had been the largest antiwar demonstrations since the Vietnam era.

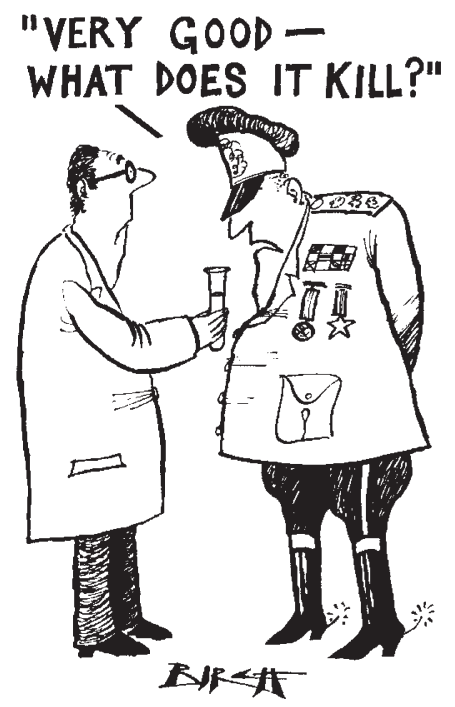

Nobody suggests that these isolated protests represent a significant national movement - at least not yet. Several factors have produced a less fertile environment for protest than the 1960 s, ranging from the more conservative outlook of most undergraduates to tight research budgets that can lead to a muting of criticism of the sources of research support.

At the same time, some see as significant the fact that each individual incident has taken place on campuses where there were fierce clashes over military research in the 1960 s and early 1970s.

University representatives lobbying the Pentagon for more research funds in Washington tend to play down the potential campus disruption. Even the protesters agree that, although anti-military feeling on campuses has grown rapidly over the past two years, it has yet to coalesce into a major source of opposition.

But the military is still treading warily. When the Defense Communications Agency agreed to sponsor a National Science Center for Communications and Electronics - largely sponsored by the private sector - to stimulate science and engineering education, it chose to concentrate its initial efforts on high schools rather than universities.

Building links with the academic

(c) I982 Macrnillan Journals L.td 